\title{
Using surface remote sensors to derive radiative characteristics of Mixed-Phase Clouds: an example from M-PACE
}

\author{
G. de Boer ${ }^{1,2,3}$, W. D. Collins ${ }^{1}$, S. Menon ${ }^{1}$, and C. N. Long $^{4}$ \\ ${ }^{1}$ Lawrence Berkeley National Laboratory, Berkeley, CA, USA \\ ${ }^{2}$ Cooperative Institute for Research of Environmental Sciences, Boulder, CO, USA \\ ${ }^{3}$ NOAA Earth System Research Laboratory, Physical Sciences Division, Boulder, CO, USA \\ ${ }^{4}$ Pacific Northwest National Laboratory, Richland, WA, USA
}

Received: 21 March 2011 - Published in Atmos. Chem. Phys. Discuss.: 20 April 2011

Revised: 28 October 2011 - Accepted: 17 November 2011 - Published: 2 December 2011

\begin{abstract}
Measurements from ground-based cloud radar, high spectral resolution lidar and microwave radiometer are used in conjunction with a column version of the Rapid Radiative Transfer Model (RRTMG) and radiosonde measurements to derive the surface radiative properties under mixedphase cloud conditions. These clouds were observed during the United States Department of Energy (US DOE) Atmospheric Radiation Measurement (ARM) Mixed-Phase Arctic Clouds Experiment (M-PACE) between September and November of 2004. In total, sixteen half hour time periods are reviewed due to their coincidence with radiosonde launches. Cloud liquid (ice) water paths are found to range between 11.0-366.4 (0.5-114.1) $\mathrm{gm}^{-2}$, and cloud physical thicknesses fall between 286-2075 m. Combined with temperature and hydrometeor size estimates, this information is used to calculate surface radiative flux densities using RRTMG, which are demonstrated to generally agree with measured flux densities from surface-based radiometric instrumentation. Errors in longwave flux density estimates are found to be largest for thin clouds, while shortwave flux density errors are generally largest for thicker clouds. A sensitivity study is performed to understand the impact of retrieval assumptions and uncertainties on derived surface radiation estimates. Cloud radiative forcing is calculated for all profiles, illustrating longwave dominance during this time of year, with net cloud forcing generally between 50 and $90 \mathrm{Wm}^{-2}$.
\end{abstract}

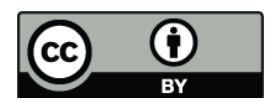

Correspondence to: G. de Boer (gdeboer@lbl.gov)

\section{Introduction}

The radiative impacts of clouds remain one of the largest uncertainties in the simulation and understanding of global climate change (IPCC, 2007). In particular, clouds occurring in the Arctic have a potentially large impact on characteristics and lifetime of sea ice (e.g. Kay and Gettelman, 2009), permafrost, and plant growth (e.g. Prowse et al., 2009). Of clouds observed at high latitudes, mixed-phase stratiform clouds, containing both ice and liquid hydrometeors, are among the most-commonly observed, longest lasting and radiatively influential cloud structures (e.g. Curry et al., 1996; Shupe et al., 2006). As discussed in Shupe et al. (2008a), observation of these clouds is inherently difficult due to the need to capture multiple phases of water simultaneously.

Despite these challenges, several previous efforts have provided estimates of Arctic stratiform cloud radiative characteristics and forcing. While obtaining this estimate is not the central goal of the present study, we do provide an overview of these studies and their methodologies for reference. Pioneering estimates of infrared radiative characteristics of summertime stratiform clouds over the Beaufort Sea were provided by Curry and Herman (1985) using a combination of radiometers, in situ measurements and a radiative transfer model. In that work, cloud emittances, absorption coefficients, reflectances, cooling rates and extinction lengths were reported. All parameters were found to be strongly tied to liquid cloud droplet size distributions assumed and cloud liquid water path (LWP). Expanding on this work, Curry and Ebert (1992) utilized measurement-based estimates of cloud fraction and microphysical properties, along with top of the atmosphere (TOA) radiative flux densities from the NASA Earth Radiation Budget Experiment (ERBE; Barkstrom et al., 1990) to calculate an annual cycle of radiative flux densities for different cloud types. Included in their analysis were "low clouds", parameterized to have mean seasonal

Published by Copernicus Publications on behalf of the European Geosciences Union. 
LWP between $10-40 \mathrm{gm}^{-2}$ and ice water paths between 0 $60 \mathrm{gm}^{-2}$. The uncertainty associated with estimating cloud droplet effective radius was mentioned to be considerable. Net surface cloud forcing was demonstrated to be positive throughout most of the year, with any negative values occurring during the summer months, when cloud-induced shortwave cooling is slightly stronger than longwave heating.

Utilizing a combination of surface-based and in situ measurements from the Beaufort and Arctic Storms Experiment (BASE), National Centers for Environmental Predication (NCEP) modeled synoptic scale properties and a twostream radiative transfer model, Pinto (1998) demonstrated good agreement between measured longwave radiative flux densities and those observed. Comparison of model calculations with clear-sky calculations demonstrated a longwave cloud radiative forcing of up to $70 \mathrm{Wm}^{-2}$. Shupe and Intrieri (2004) provide cloud radiative forcing calculations for an annual cycle of clouds observed during the Surface Heat Budget of the Arctic (SHEBA; Uttal et al., 2002), analyzing individual contributions of cloud properties on long and shortwave forcing for observed clouds. They found that clouds with significant longwave impacts were generally low clouds with warmer base temperatures, with longwave cloud forcing impacted strongly by LWP. Except during mid-summer, they found that longwave effects dominate up to LWP values of $400 \mathrm{gm}^{-2}$. They also demonstrated that for clouds containing liquid water, the longwave forcing dominates net cloud forcing on an annual scale, resulting in a peak in the annual distribution of net cloud radiative forcing of approximately $50 \mathrm{Wm}^{-2}$. The largest net cloud radiative forcing was demonstrated to occur during fall, when liquid clouds are thickest and solar radiation is reduced. An annual distribution of longwave cloud forcing for liquid-containing clouds was found to peak at $50-70 \mathrm{Wm}^{-2}$. Summer cloud radiative forcing was also evaluated by Dong and Mace (2003). Utilizing surface remote sensors at Barrow for May-September, they found the net radiative forcing by stratus clouds to become negative starting in late May, and stay negative until early September. The forcing was found to peak during June and July, with values up to $-150 \mathrm{Wm}^{-2}$. Stratus cloud longwave radiative forcing was found to range between roughly $40-70 \mathrm{Wm}^{-2}$ during that time period.

In the current effort, we utilize modern measurement and retrieval methods from a combination of ground-based remote sensors used during the Mixed-Phase Arctic Cloud Experiment (M-PACE; Verlinde et al., 2007) to derive surface radiative characteristics under mixed-phase cloud conditions observed during this campaign. Instruments included are the DOE Millimeter Cloud Radar (MMCR), the University of Wisconsin High Spectral Resolution Lidar (AHSRL) and a microwave radiometer (MWR). While surface radiative measurements are available for this time period, our main focus is characterizing the ability of a combination of remotelysensor measurements and a column version of the advanced Rapid Radiative Transfer Model (RRTMG; Clough et al.,
2005) to derive the surface radiative flux densities. We quantify the sensitivity of this technique to retrieval assumptions, and put it forward as a substitute for traditional radiometric measurements in historical or future datasets where radiometric measurements are lacking, limited, or of poor quality. Use of remotely-sensed measurements for calculating radiative properties provides more information about the vertical structure of the clouds than surface radiation measurements alone, and can be useful in the evaluation of new retrieval methods through radiative closure studies. To provide a thorough characterization, we additionally perform experiments analyzing this method's sensitivity to less frequently measured quantities such as surface temperature and surface albedo. An overview of methods and tools utilized is provided in the following section. This is followed by an overview of M-PACE clouds studied, an analysis of derived surface flux density estimates, a sensitivity analysis and cloud radiative forcing calculations. Finally a summary is provided.

\section{Measurement period and methods}

M-PACE was a United States Department of Energy (DOE) Atmospheric Radiation Measurement (ARM) experiment carried out along the north slope of Alaska (NSA) during September through November of 2004 aimed at collecting a focused set of observations to better understand Arctic mixed-phase clouds. Measurements used in this evaluation were collected at Barrow $\left(71.3^{\circ} \mathrm{N}, 156.6^{\circ} \mathrm{W}\right)$. The current approach requires observations taken close to a radiosonde sampling time (00:00 Z and 12:00 Z). With this restriction 16 cases featuring single-layer mixed-phase stratiform clouds were identified, covering a wide variety of cloud thicknesses, as well as liquid and ice water paths (LWP and IWP, respectively) for both day and nighttime periods (see Table 1). Also included in Table 1 are the volumetric and optical ice fractions for these clouds. The volumetric ice fraction is calculated as the ratio between the IWP and the total water path (IWP + LWP), while the optical ice fraction is calculated as the ratio of the optical thickness of the ice component and the total cloud optical thickness (ice + liquid), as calculated by Eqs. (3) and (4).

\subsection{Instruments and retrievals}

To derive cloud properties, we utilized a combination of ground based remote sensors and information from launched radiosondes. The microphysical retrieval techniques implemented are similar to those described in de Boer et al. (2009) and Shupe et al. (2008b), using the University of Wisconsin Arctic High Spectral Resolution Lidar (AHSRL; Eloranta, 2005), a 35-GHz Millimeter Cloud Radar (MMCR; Moran et al., 1998) and microwave radiometer (MWR). Our focus on mixed-phase stratiform clouds is due in part to 
Table 1. Case overview providing case numbers, the time periods covered, and values for case mean liquid cloud depth, case mean liquid water path and case mean ice water path.

\begin{tabular}{lrrrrrr}
\hline Case & Time Period & $\overline{\Delta Z}_{\text {liq }}(\mathrm{m})$ & $\overline{\mathrm{LWP}}\left(\mathrm{gm}^{-2}\right)$ & $\overline{\overline{\mathrm{IWP}}}\left(\mathrm{gm}^{-2}\right)$ & $\overline{f_{i, \text { vol }}}(\%)$ & $\overline{f_{i, \text { opt }}}(\%)$ \\
\hline 1 & $23: 45,29$ Sep-00:15, 30 Sep & 692 & 155.0 & 35.4 & 18 & 5 \\
2 & $11: 45$, 1 Oct-12:15, 1 Oct & 754 & 43.1 & 132.7 & 72 & 33 \\
3 & $11: 45,4$ Oct-12:15, 4 Oct & 771 & 162.2 & 1.2 & 1 & 0 \\
4 & $23: 45,8$ Oct-00:15,9 Oct & 934 & 352.4 & 108.7 & 24 & 8 \\
5 & $11: 45,9$ Oct-12:15,9 Oct & 828 & 274.3 & 13.0 & 4 & 2 \\
6 & $23: 45,9$ Oct-00:15, 10 Oct & 812 & 229.4 & 115.2 & 32 & 9 \\
7 & $11: 45,10$ Oct-12:15, 10 Oct & 764 & 182.4 & 16.8 & 8 & 2 \\
8 & $23: 45,11$ Oct-00:15, 12 Oct & 619 & 121.8 & 52.4 & 30 & 8 \\
9 & $11: 45,12$ Oct-12:15, 12 Oct & 1144 & 210.3 & 42.9 & 16 & 5 \\
10 & $23: 45,12$ Oct-00:15, 13 Oct & 744 & 146.3 & 77.2 & 32 & 9 \\
11 & $23: 45,29$ Oct-00:15,30 Oct & 803 & 106.0 & 62.1 & 33 & 11 \\
12 & $23: 45,30$ Oct-00:15,31 Oct & 412 & 26.8 & 6.3 & 19 & 6 \\
13 & $11: 45,2$ Nov-12:15, 2 Nov & 734 & 110.6 & 21.6 & 16 & 5 \\
14 & $11: 45,5$ Nov-12:15, 5 Nov & 1547 & 70.4 & 202.2 & 74 & 42 \\
15 & $11: 45,6$ Nov-12:15, 6 Nov & 262 & 11.0 & 0.5 & 5 & 2 \\
16 & $23: 45,7$ Nov-00:15, 8 Nov & 726 & 138.4 & 2.0 & 1 & 1 \\
\hline
\end{tabular}

the challenge they present to microphysical retrieval algorithms. Retrievals implemented generally represent stateof-the-science attempts, as recommended by Shupe et al. (2008a), and outlined here.

To begin, cloud boundaries are determined using the cloud radar and lidar. A combination of AHSRL backscatter crosssection and depolarization is used to find the base of the liquid component of the cloud $\left(Z_{\text {base }}\right)$. All ice found below that is assumed to be precipitation. Because the lidar signal is often completely attenuated within the cloud layer, MMCR reflectivity is used to find cloud top $\left(Z_{\text {top }}\right)$. It is important to note that due to near-field limitations of the radar, observations below $200 \mathrm{~m}$ are not included in any of the analysis presented. Cloud base and top temperatures for each profile are derived using this information in combination with radiosonde temperature measurements.

Ice water content (IWC) is calculated using an empirical relationship from radar reflectivity $\left(Z_{\mathrm{mmcr}}\right)$ as prescribed in Shupe et al. (2006). The relationship used is:

$\mathrm{IWC}=0.07 Z_{\mathrm{mmcr}}^{0.63}$

While this equation is empirical, and tuned to measurements taken during the Surface Heat Budget of the Arctic Ocean campaign (SHEBA, Uttal et al., 2002), it is generally the best option available, since multi-sensor retrievals are limited by attenuation of the lidar and a liquid-dominated lidar backscatter signal. While a similar relationship was derived specifically for M-PACE in Shupe et al. (2008b), with the only change being an updated leading coefficient ( 0.04 instead of 0.07), the SHEBA relationship is believed to be more universally applicable and is therefore used here. The sensitivity of radiative estimates to this relationship is explored in Sect. 3.3.
Because the liquid cloud can not necessarily be detected by the radar, and attenuation hinders lidar measurements, liquid water content (LWC) is calculated using a scaledadiabatic assumption (Zuidema et al., 2005). Utilizing radiosonde temperature information, the pseudo-adiabatic lapse rate $\left(\Gamma_{s}\right)$ for a cloud is calculated. From this, we calculate liquid water mixing ratio $\left(w_{1}\right)$ via integration of:

$d w_{1}=\frac{c_{p}}{L_{l, v}}\left(\Gamma_{s}+\frac{g}{c_{p}}\right) d z$

with $c_{p}$ being the specific heat of air at a constant pressure, $\mathrm{L}_{l, v}$ the latent heat of vaporization, $z$ the altitude, and $g$ the acceleration due to gravity. Multiplication of the liquid water mixing ratio by the air density results in an estimate of LWC. Since these clouds are not necessarily adiabatic, we scale the calculated profile using LWP derived from MWR measurements. Because this method depends on accurate temperature measurements, we can only calculate these properties close to radiosonde launches, and have limited our analysis here to $+/-15 \mathrm{~min}$ from the radiosonde analysis time.

Ice and liquid hydrometeor effective sizes are more challenging to derive. For ice effective particle size $\left(r_{\mathrm{e}}\right.$,ice $)$, we utilize a multi-instrument retrieval (AHSRL and MMCR) as described in Donovan and van Lammeren (2001), using the ratio of lidar and radar backscatter to estimate particle effective size. This technique requires an assumed ice crystal habit governing the power law relationship used to relate ice crystal size and volume (e.g. Mitchell, 1996). This size retrieval can only be done below the liquid portion of the cloud due to dominance of the lidar signal by the liquid component of the mixed-phase cloud. Therefore, once inside the cloud layer, we utilize a scaling factor based on the ratio of radar reflectivity just below cloud base to radar reflectivity throughout 
the cloud. This ratio is raised to the $1 / 6$ th power, since radar backscatter cross section is proportional to $r^{6}$. Values of $r_{\mathrm{e}}$,ice within the cloud layer are then calculated using this scaling factor and the below cloud $r_{\text {e,ice }}$. Liquid droplet effective radius $\left(r_{\mathrm{e}, \mathrm{liq}}\right)$ is not constrained, since we can not observe the depth of the liquid component of the cloud. Therefore, we calculate a profile of $r_{\mathrm{e}}$, liq that assumes an initial cloudbase droplet size, and scales to the LWC profile, assuming a constant droplet number concentration calculated using this cloud-base droplet size and LWC.

An example of the measurements and retrievals is provided in Fig. 1. Included in the top half of Fig. 1 are plots of AHSRL-measured backscatter cross-section ( $\beta^{\prime}$, top) and depolarization $(\delta$, middle), as well as MMCR reflectivity $\left(Z_{\mathrm{mmcr}}\right.$, bottom). The data have been averaged to 2-min intervals in order to reduce noise and variability in the information passed into the radiative transfer model. Higher values of $\beta^{\prime}$ observed at roughly $500-800 \mathrm{~m}$ are the result of liquid droplets. Because of the concentration of these droplets, they have a large combined backscatter cross-section. AHSRL $\delta$ is used to help determine cloud phase, with lower depolarization ratios generally resulting from spherical scatterers. Due to the thickness of the liquid portion of this cloud, the lidar signal is attenuated before reaching cloud top. This is seen in $Z_{\mathrm{mmcr}}$, which demonstrates detected hydrometeors up to roughly $1300 \mathrm{~m}$. Because of the longer wavelength utilized, the MMCR is more sensitive to ice crystals, and likely can not detect cloud-top liquid droplets. However, in situ and remote-sensing studies have demonstrated that ice crystals generally extend up to cloud top (e.g. de Boer et al., 2008; McFarquhar et al., 2007), and that radar is capable of detecting cloud top altitude.

The lower half of Fig. 1 illustrates profiles of retrieved liquid and ice water content, as well as liquid and ice particle sizes for the 10 October case. These provide some perspective on the variability between individual profiles within a case. Because of the pseudo-adiabatic assumption applied to the liquid portion of the cloud, liquid properties vary relatively linearly with altitude. Ice properties demonstrate more variability with altitude.

\subsubsection{RRTMG}

RRTMG is a global climate model version of the rapid radiative transfer model (RRTM). It calculates long and shortwave flux densities utilizing a correlated-k method for computational efficiency. It has been demonstrated to be accurate when compared to line-by-line radiative calculations. Parts of RRTM are currently implemented in the European Center for Medium-Range Weather Forecasts (ECMWF) and National Centers for Environmental Prediction (NCEP) Global Forecast System (GFS) models, as well as the latest version of the National Center for Atmospheric Research (NCAR) Community Climate System Model (CCSM4) as part of the Community Atmosphere Model (CAM). In this work, re- trieved profiles of LWC, IWC, $r_{e, \text { ice }}$, and $r_{e}$,liq, solar zenith angle, surface temperature and albedo are used to drive a column version of RRTMG. Solar zenith angle is calculated for each given date and time, along with the earth's radius at Barrow's latitude. One drawback of using RRTMG in this evaluation is that the model assumes a plane-parallel atmosphere. Because of the high sun-angles involved, the attenuation of the solar beam is likely overestimated because of an increase in the atmospheric path length resulting from the plane-parallel assumption. Finally, assigned profiles of carbon dioxide, ozone, nitrous oxide, carbon monoxide and methane included with the RRTM package are based on a sub-Arctic atmosphere. A profile of water vapor is determined directly from the radiosonde measurements.

\section{Analysis}

\subsection{Derived cloud properties}

Although only a small sample, clouds observed close to radiosonde launches during M-PACE cover a variety of mixedphase stratiform conditions. Estimates of mean cloud thickness $\left(\Delta Z_{\text {liquid }}\right)$, mean cloud LWP and mean cloud IWP are provided in Table 1 for each of the 16 cases analyzed. Figure 2 provides additional insight into variability between and within cases. For each quantity, boxplots are laid out with the black line representing the mean, shaded boxes representing the interquartile range (IQR) and whiskers representing $1.5 \times$ IQR beyond the 25 th and 75 th percentiles (roughly $2.7 \sigma$ for normally distributed datasets) for measured profiles within each case. Points outside of this range are represented by open circles. It is important to note that 2 -min averaging results in only 6 to 15 profiles per case (depending on instrument calibrations and uptime), meaning small sample sizes for the distributions shown. Cloud base temperature for these cases was found to vary between 253-272 K. Due to the stratiform nature of the clouds, temperature generally did not vary very much within each case. Cases 11-16, occurring later in the year (end of October, beginning of November) had the coldest recorded temperatures.

Liquid cloud thickness varied between 300 and $1600 \mathrm{~m}$, and within case 2 , varied up to $400 \mathrm{~m}$. Generally, clouds were found to be around $800 \mathrm{~m}$ thick. Retrieved LWP also varied substantially between cases, ranging from roughly $10 \mathrm{gm}^{-2}$ to over $350 \mathrm{gm}^{-2}$. With the exception of cases 12 and 15 , these clouds contained enough liquid (in a mean sense) to emit as grey bodies. The LWP threshold for this was demonstrated to be around $30 \mathrm{gm}^{-2}$ by Shupe and Intrieri (2004), with further increases in LWP having no impact on downwelling longwave radiation.

As discussed above, liquid droplet effective radii were constrained by measured LWP, via the scaled liquid water content. In Fig. 2, all cases were assumed to have cloud droplet effective radii of $3.5 \mu \mathrm{m}$ at cloud base, and grow 


\section{October 2004}
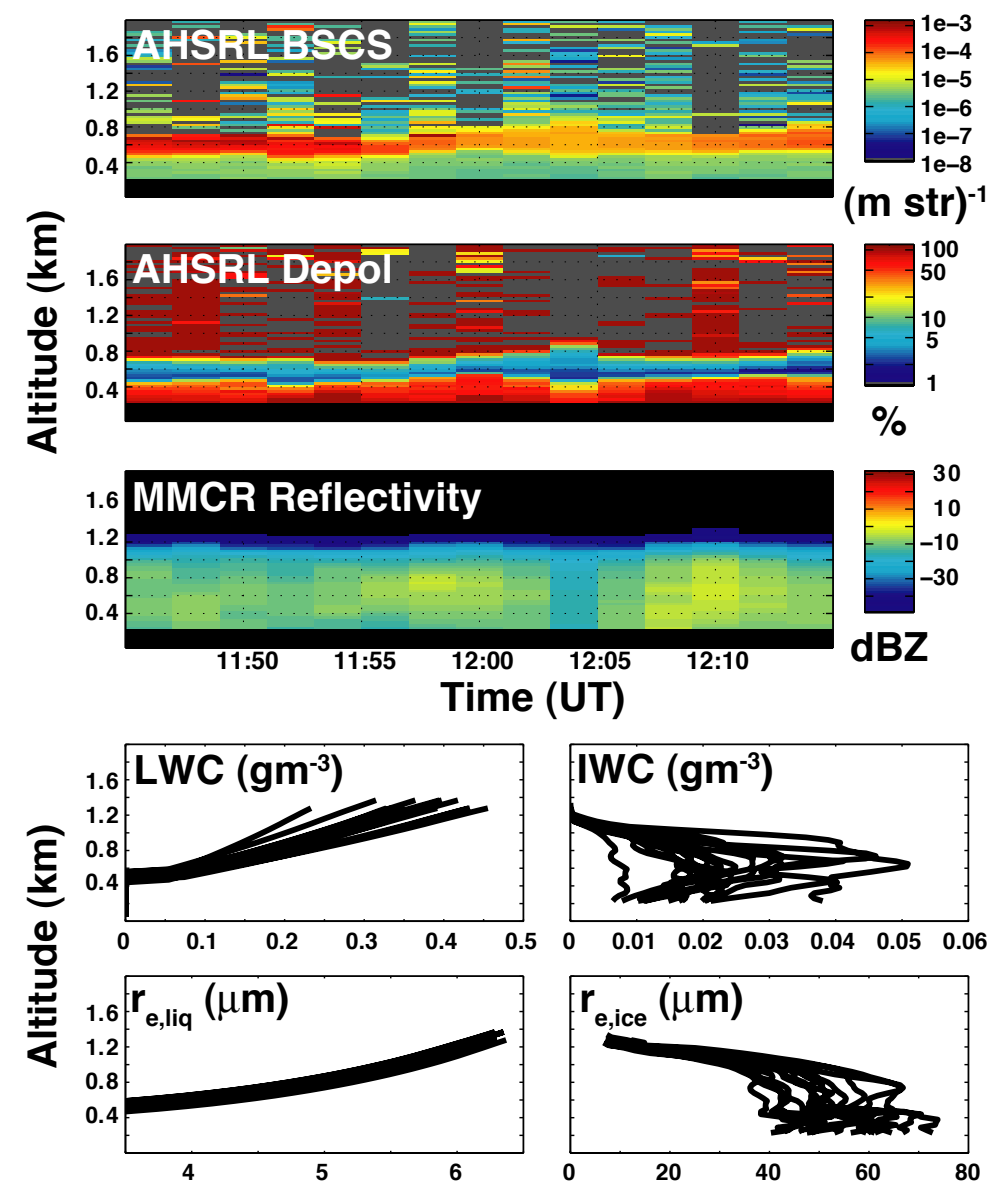

Fig. 1. Measured and retrieved cloud properties on 10 October 2004. Included are (top to bottom) AHSRL bacscatter cross-section, AHSRL depolarization ratio, MMCR reflectivity, and profiles of liquid water content (LWC), ice water content (IWC) and liquid $\left(r_{e}\right.$,liq $)$ and ice $\left(r_{e, \text { ice }}\right)$ effective particle sizes.

larger with height. Therefore, it is not surprising that mean cloud droplet effective radius $\left(\bar{r}_{e, \text { liq }}\right)$ appears to scale with cloud physical depth. Using this initial value, $\bar{r}_{e}$, liq ranged from roughly $4-5.8 \mu \mathrm{m}$.

Ice water paths were found to vary quite widely, both between cases and within individual cases. Across the dataset, values varied between roughly $0.5-200 \mathrm{gm}^{-2}$, though with the exception of case 14, case mean values did not exceed $135 \mathrm{gm}^{-2}$. Mean ice particle effective radii $\left(\bar{r}_{e, \text { ice }}\right)$ were estimated to fall between $15-80 \mu \mathrm{m}$. Generally, variability for any individual case was small (with exception of case num-

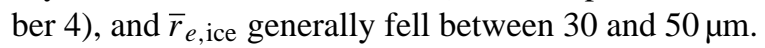

\subsection{RRTMG derived flux densities}

Initial analysis is completed on all 16 cases, assuming cloudbase $r_{e, \text { liq }}$ of $3.5 \mu \mathrm{m}$, bullet rosettes as the ice crystal habit, and using retrieved cloud properties. Surface albedos for each case were calculated from surface radiometric data, with case-mean values ranging between 0.67 and 0.86 . Finally, ground temperature was obtained from the National Oceanographic and Atmospheric Administration's (NOAA) US Climate Reference Network station at Barrow, which uses a Apogee Instruments IRTS-P infrared (IR) temperature sensor mounted on a tower at $1.3 \mathrm{~m}$ above ground level. An evaluation of RRTMG-derived flux densities is completed using QCRAD, a quality-controlled surface radiation estimate product available through the ARM program database (Long and Shi, 2008). Long and Turner (2008) report estimates of the 2-sigma uncertainties of the 1-min ARM measurements are 3 or $4 \mathrm{Wm}^{-2}, 6 \%$ or $20 \mathrm{Wm}^{-2}, 6 \%$ or $10 \mathrm{Wm}^{-2}$, and $2.5 \%$ or $4 \mathrm{Wm}^{-2}$ (whichever value, the given $\mathrm{Wm}^{-2}$ or percent of signal, is largest for each) for the downwelling diffuse SW, direct normal SW, total (global) SW, and LW, 

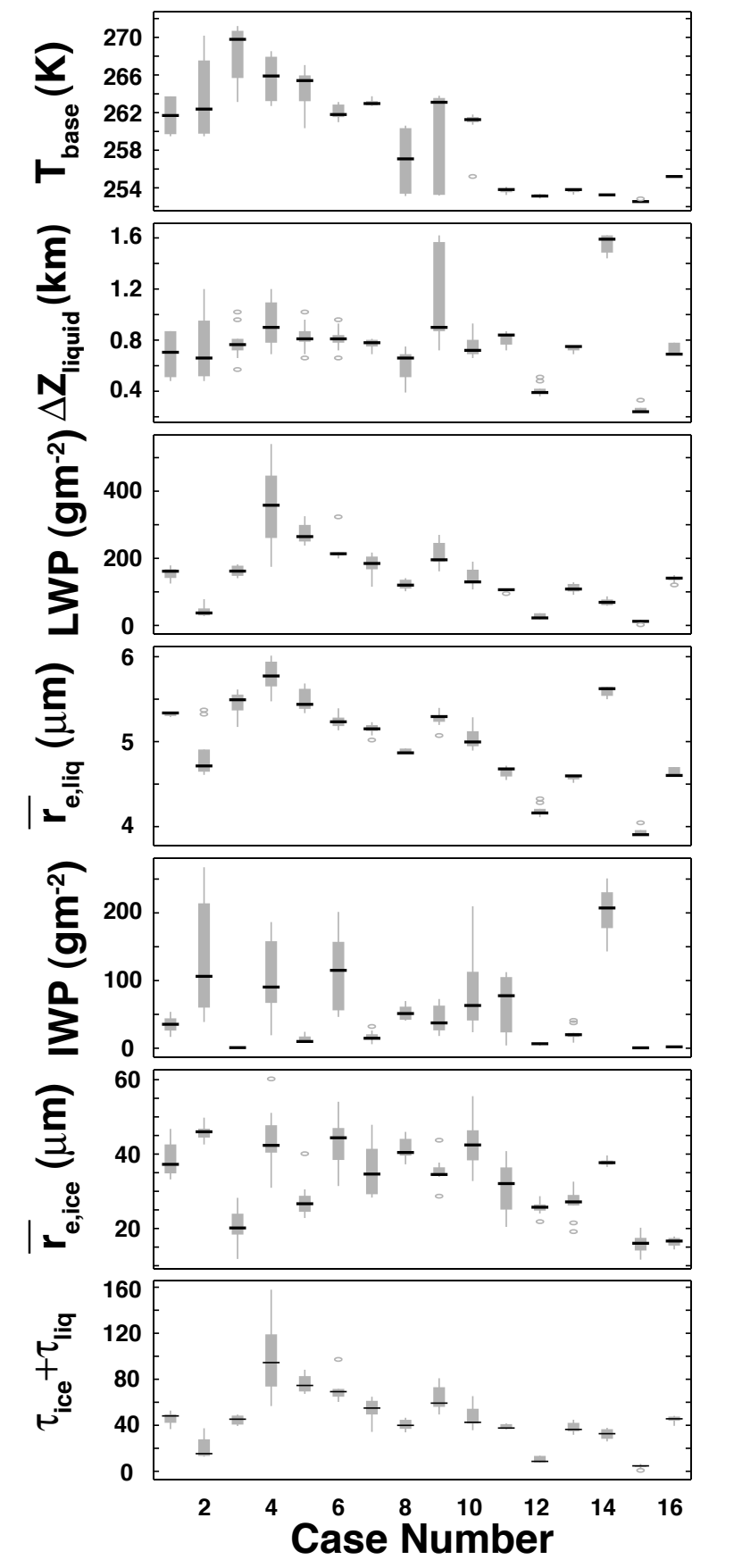

Fig. 2. Distributions of retrieved (top to bottom) cloud base temperature $\left(T_{\text {base }}\right)$, liquid cloud thickness $\left(\Delta Z_{\text {liquid }}\right)$, liquid water path (LWP), mean liquid droplet effective radius $\left(\bar{r}_{e, \text { liq }}\right)$, ice water path (IWP), and mean ice crystal effective radius $\left(\bar{r}_{e, \text { ice }}\right)$ for all included cases.

respectively as derived from Stoffel (2005). Results of this evaluation are shown in Fig. 3. Shortwave (wavenumbers between 820 and $50000 \mathrm{~cm}^{-1}$ ) and longwave (wavenumbers between 10 and $3250 \mathrm{~cm}^{-1}$ ) flux densities are shown, and

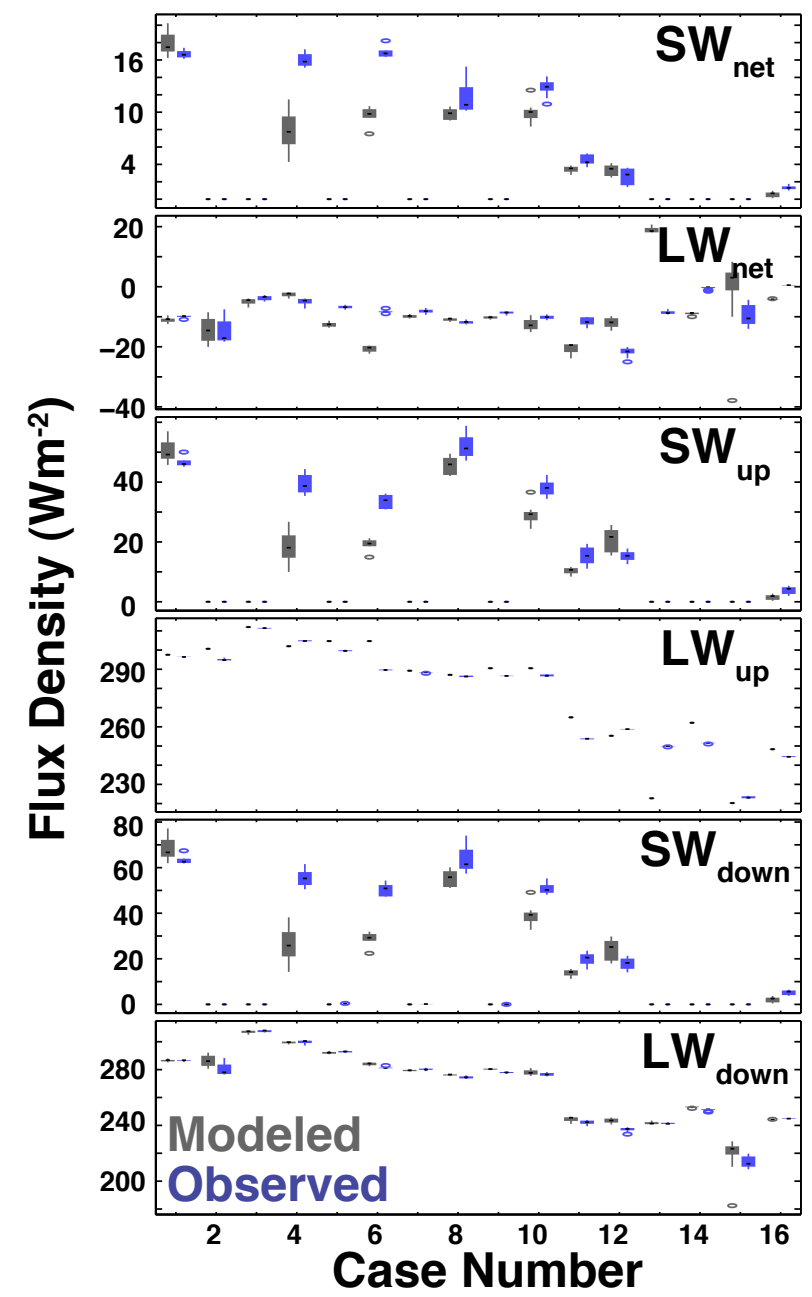

Fig. 3. Distributions of modeled (grey) and measured (blue) surface radiative flux densities. From top to bottom: net shortwave ( $\mathrm{SW}_{\text {net }}$ ), net longwave ( $\left.\mathrm{LW}_{\text {net }}\right)$, upward shortwave $\left(\mathrm{SW}_{\text {up }}\right)$, upward longwave $\left(\mathrm{LW}_{\mathrm{up}}\right)$, downward shortwave $\left(\mathrm{SW}_{\mathrm{down}}\right)$, and downward longwave $\left(\mathrm{LW}_{\mathrm{down}}\right)$. The dots represent the case mean, the thick bar the 25 th/75th percentiles, and the whiskers representing $1.5 \times$ IQR beyond 25 th and 75 th percentiles. Any values outside of that range are indicated by open circles.

broken down into surface downwelling, upwelling and net components. Each case features two distributions, with boxplots plotted identically to Figure 2. Outlying values (values outside of the IQR+/-1.5 $\times$ IQR) are shown by open circles. The sign convention used results in positive net values at the surface when downwelling flux density is larger than upwelling flux.

Generally speaking, intra-case variability is found to be greatest for surface shortwave radiation, with net surface shortwave flux densities changing by as much as $20 \mathrm{Wm}^{-2}$. General patterns observed were replicated in the modeled 
data. The best agreement was found for downwelling longwave radiation, with a root-mean-squared error (RMSE) of $4.48 \mathrm{Wm}^{-2}$. The upwelling longwave estimates had larger errors (RMSE of $9.18 \mathrm{Wm}^{-2}$ ), likely due to errors in the surface temperature estimates used. Combined, these result in RMSE of 9.83 in the net surface longwave flux densities. For all of these quantities, it should be noted that the majority of the error seems to come from a small subset of the cases, with cases 11,13 and 14 having the largest differences between modeled and observed surface flux densities. As is shown in Fig. 2, these cases feature some of the smallest LWP observed. Shortwave errors were generally larger. RMSEs for downwelling, upwelling and net shortwave radiation were $9.93,7.27$ and $2.78 \mathrm{Wm}^{-2}$, respectively. These numbers are muted due to contributions from nighttime cases, where both modeled and observed flux densities were zero. Removing nighttime cases, these values were increased to $14.43,10.57$ and $4.04 \mathrm{Wm}^{-2}$. Some of this error is likely due to the assumption of a plane-parallel atmosphere employed in RRTMG.

Error magnitude was also plotted against visible optical depth for each case (Fig. 4). The optical depths were computed separately for the liquid and ice components using relationships from Stephens (1994) and Ebert and Curry (1992), respectively. The relationship for liquid is:

$\tau_{\mathrm{vis}, \mathrm{liq}} \approx \frac{3 \mathrm{LWP}}{2 \rho_{l} r_{e, \text { liq }}}$

where $\tau_{\text {vis,liq }}$ is the visible optical depth for liquid, LWP is the liquid water path, $\rho_{l}$ is the density of water, and $r_{e}$, liq is the droplet effective radius. For ice, the relationship is:

$\tau_{\mathrm{vis, \text {ice }}} \approx \operatorname{IWP}\left[a+\frac{b}{r_{e, \text { ice }}}\right]$

where $\tau_{\text {vis,ice }}$ is the visible optical depth for ice, IWP is the ice water path, $r_{e}$,ice is the ice crystal effective size, and $\mathrm{a}$ and $\mathrm{b}$ are wavelength-dependent parameters (available in Ebert and Curry (1992), for visible wavelengths $\mathrm{a}=3.448 \times 10^{-3} \mathrm{~m}^{2} \mathrm{~g}^{-1}$ and $\left.\mathrm{b}=2.431 \mu \mathrm{m} \mathrm{m}^{2} \mathrm{~g}^{-1}\right)$.

For shortwave flux densities illustrated in Fig. 4, it appears that errors in both up- and downwelling flux densities increase with increasing $\tau_{\text {vis }}$ for both liquid and ice. Generally, shortwave flux densities appear to be underestimated by the technique used. The cluster of cases that demonstrate zero error are the result of dark or very low-light cases, with nighttime cases (solar zenith angle $\geq 90^{\circ}$ ) illustrated in red. Errors in up- and downwelling components look very similar to one another due to the upwelling component simply being proportional to the downwelling by the albedo. It also appears as though clouds with lower LWP provide more difficulties for the model than thicker clouds, and that clouds with low $\tau_{\text {vis,ice }}$ are the only ones that over predict incoming (and therefore outgoing) shortwave radiation. Net shortwave flux density errors are generally less than $10 \mathrm{Wm}^{-2}$.

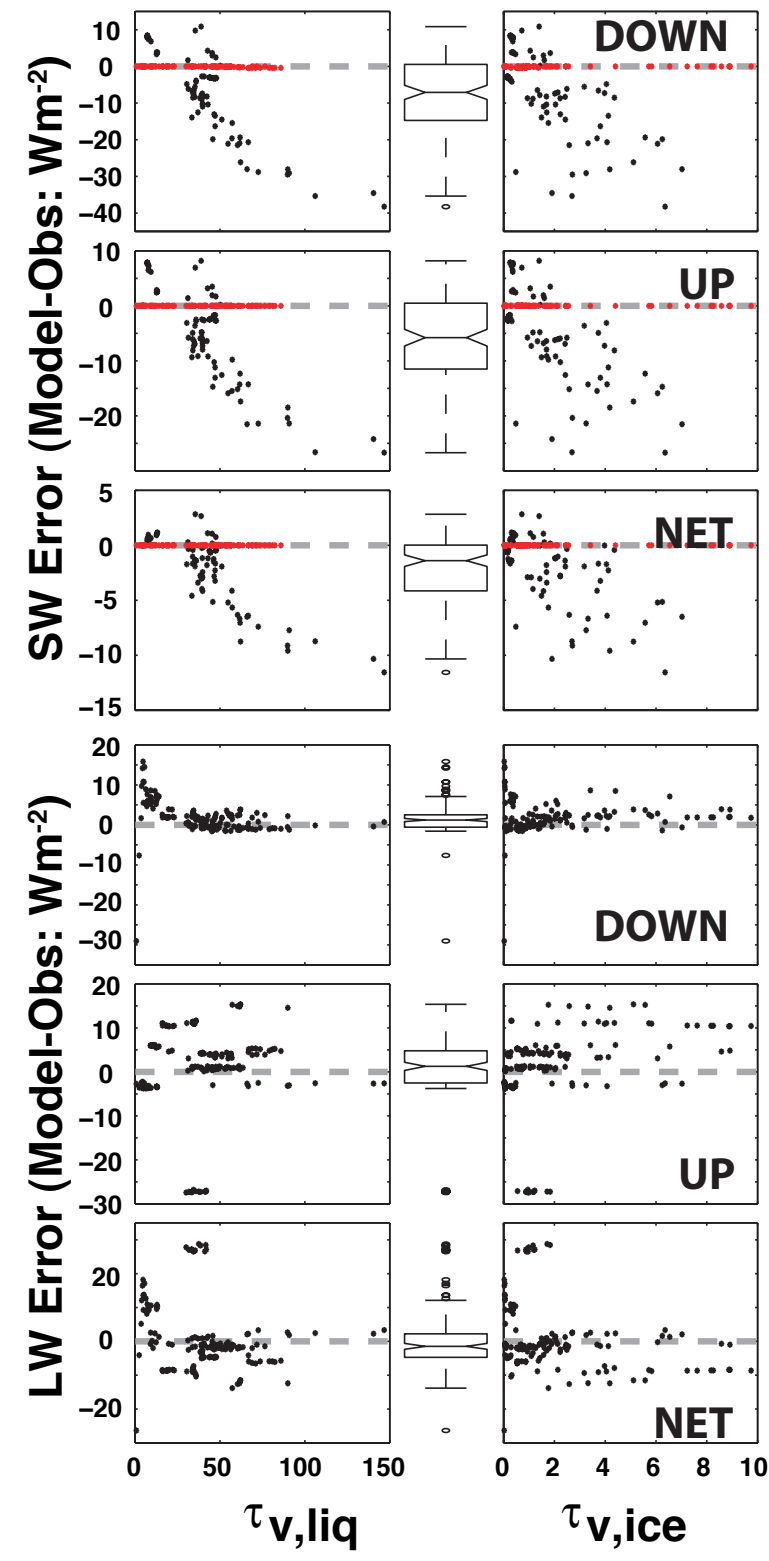

Fig. 4. Errors in modeled surface shortwave (SW, top three rows) and longwave (LW, bottom three rows) compared with liquid ( $\tau_{v \text {, liq }}$, left) and ice $\left(\tau_{v}\right.$,ice, right) visible optical thickness. Boxplots in between the liquid and ice comparisons provide error statistics, demonstrating the mean (center notch), IQR (ends of boxes), $1.5 \times$ IQR beyond 25 th and 75 th percentiles (ends of whiskers) and outliers (circles). For shortwave analysis, nighttime cases (red) are not included in the boxplots.

For longwave flux densities, again the errors in net surface radiative flux density are relatively small (generally $<10 \mathrm{Wm}^{-2}$ ). Downwelling longwave flux densities seem to be over-predicted, with errors $<3 \mathrm{Wm}^{-2}$ for cases with larger $\tau_{\text {vis,liq. }}$. Cases with smaller $\tau_{\text {vis,liq }}$ have errors up to 
roughly $10 \mathrm{Wm}^{-2}$. The center column of Fig. 4 illustrates boxplots (similarly laid out to Fig. 2) illustrating the distribution of errors for each flux density component. For shortwave flux densities, nighttime errors were not included in these boxplots.

\subsection{Sensitivity analysis}

In order to assess the sensitivity of these estimates to retrieval error and missing measurements, 56 sensitivity experiments were completed. Retrievals were re-calculated modifying a series of different quantities, including the ice crystal habit assumed, the liquid droplet effective size at cloud base, the MWR-retrieved LWP, and the radar derived IWC. The ice crystal habit was varied between bullet rosettes, spheres and broad-branched crystals, changing the coefficients for the power-law relationships used to retrieve the ice crystal effective size. Liquid droplet effective size was tested at both $3.5 \mu \mathrm{m}$ (lower limit acceptable for RRTMG), and $6.5 \mu \mathrm{m}$. Since this droplet size is what is assumed at cloud base, it should be indicative of a newly nucleated droplet. With some assumptions about aerosol composition, a $3.5 \mu \mathrm{m}$ droplet would nucleate on an aerosol particle of 0.2 (0.4) $\mu \mathrm{m}$ at $0.1(1.0) \%$ supersaturation with respect to water. The $6.5 \mu \mathrm{m}$ size was chosen as a realistic upper limit, with droplets of that size forming on aerosol particles with radii of $0.4(1.0) \mu \mathrm{m}$ at $0.1(1.0) \%$ supersaturation with respect to water (de Boer et al., 2010). In changing droplet size, LWP was always held to the measured value, resulting in variable liquid optical depths. While not presented here, the range covered by these optical depths can be calculated using Eq. (3). LWP values were varied by $+/-25 \mathrm{gm}^{-2}$, the derived uncertainty for this method (Westwater et al., 2001). The sensitivity to retrieved IWC was evaluated in two ways. First, IWC derived by the MMCR was varied by $+/-75 \%$, the uncertainty derived for this method by Shupe et al. (2006). Second, sensitivity to the leading coefficient used in the empirical Z-IWC relationship was evaluated. This was done based on the use of 0.04 as a leading coefficient for M-PACE clouds in Shupe et al. (2008b). Finally, an overall analysis of all possible combinations of these perturbations was performed to derive net retrieval sensitivity. Please note that the impact of the leading coefficient in the IWC retrieval was not included in this net analysis. The quantity used to illustrate the sensitivity is the difference in derived flux densities under perturbed conditions from those derived assuming the base conditions described at the start of Sect. 3.2.

Results from this evaluation are shown in Fig. 5 for downwelling long- (blue) and shortwave (red) flux densities. Since upwelling longwave flux density is simply a function of surface temperature and upwelling shortwave flux density is a function of surface albedo, differences in these values are not evaluated here. As with other box plots, the mean value is shown by the black line, the IQR is represented by the box, and 1.5xIQR beyond the 25th and 75th percentiles is represented by the whiskers. For this figure, outliers are not shown. In general, uncertainties in liquid property retrievals impact estimates more strongly than those associated with ice. With the exception of sensitivity associated with the liquid droplet effective radius, variability is generally less than $15 \mathrm{Wm}^{-2}$ for individual parameters, based on the IQR+/-1.5 $\times$ IQR derived from all profiles.

Changes in assumed ice crystal habit appear to impact shortwave flux density estimates at a level comparable to changes in cloud LWP. However, while uncertainty of LWP estimates is well quantified, no such information is available for ice crystal shape in these mixed-phase stratiform clouds. Despite this, it is unlikely that either spherical ice or broadbranched crystals are truly representative of the distribution of ice crystal shapes found, resulting in an extreme estimate of sensitivity. Liquid droplet size has a larger impact, particularly on shortwave flux densities. In addition to these shortwave sensitivities, there are also some minimal impacts on longwave downwelling radiation. For the thinnest cases sampled, cloud impact on downwelling longwave radiation is not as dominant as for thicker clouds. In these instances, increasing $r_{e}$,iq decreases cloud optical depth, resulting in an increased contribution to downwelling surface longwave flux density from the clear sky above cloud level, reducing the effective atmospheric radiating temperature. This results in decreased flux density at the surface with increasing $r_{e}$,liq. Changing LWP impacts shortwave flux densities through changes in cloud optical depth, while also altering the surface downwelling longwave flux density. IWC has the smallest impact on the surface flux densitites. Sensitivity to the leading coefficients $\left(\mathrm{IWC}_{\mathrm{C}}\right.$ ) previously presented in the literature for Z-IWC relationships (0.04 and 0.07) has minimal impact on the surface radiation. A more thorough retrieval uncertainty number of $75 \%\left(\mathrm{IWC}_{\mathrm{U}}\right)$ causes slightly larger deviations, but even those are small compared to those resulting from liquid water property uncertainties. To evaluate the relative importance of ice properties, all cases were run with ice influences removed. The result of this comparison is shown on the far right of Fig. 5, with ice removal resulting in increased downwelling shortwave radiation of 0 $5 \mathrm{Wm}^{-2}$, and decreased downwelling longwave radiation of $0-8 \mathrm{Wm}^{-2}$. These changes are generally small when compared to the absolute magnitude of flux density, meaning that the ice contribution to the radiative profile is generally a small one. Despite relatively large IWP, this is not surprising given the limited amount that ice contributes to the total optical depth (see $f_{i \text {,opt }}$, Table 1). Evaluating the impact of all possible combinations of the four left-most parameters presented (i.e. not including $\mathrm{IWC}_{\mathrm{C}}$ ) results in uncertainties of roughly $10 \mathrm{Wm}^{-2}$ (IQR) in the shortwave flux density and $4 \mathrm{Wm}^{-2}$ (IQR) in the longwave.

While outside of the cloud property retrievals, surface characteristics also impact the surface radiation budget. As would be expected, surface shortwave flux densities demonstrate significant sensitivity to the assumed surface albedo. 


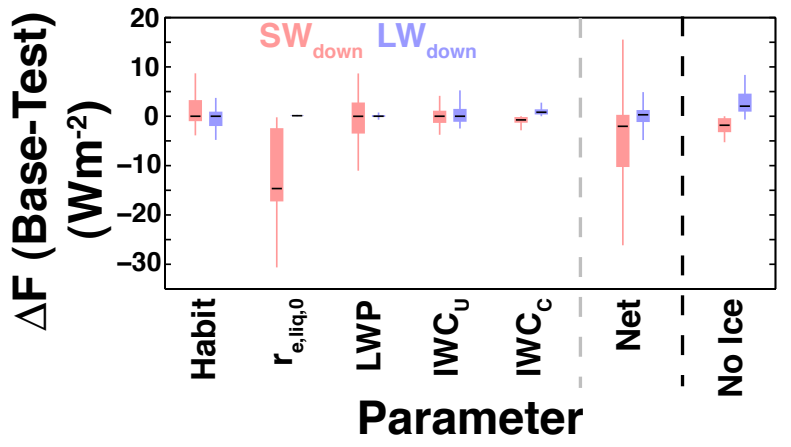

Fig. 5. Distributions of differences between downwelling shortwave (red) and longwave (blue) flux densities derived using base parameters (see text for details), and those derived with alternate values for the parameters shown. $\mathrm{IWC}_{\mathrm{U}}$ represents the sensitivity of surface flux densities to IWC retrieval uncertainty, while $\mathrm{IWC}_{\mathrm{C}}$ represents the sensitivity to the coefficient used in the empirical relationship. $\mathrm{IWC}_{\mathrm{C}}$ is not accounted for in the net calculation shown. The no ice calculation on the far right compares clouds with ice included in radiative transfer calculations, and the same clouds with ice removed. The mean value is indicated by the black line in each distribution, the box indicates the IQR, and the whiskers represent $1.5 \times \mathrm{IQR}$ beyond the 25 th and 75 th percentiles. Outliers are not shown, and nightime cases are omitted in the shortwave evaluation.

Changes in downwelling shortwave flux density of up to $80 \mathrm{Wm}^{-2}$ and up to $100 \mathrm{Wm}^{-2}$ in the upwelling surface shortwave radiative flux density result from changes in the surface albedo between $95 \%$ and $50 \%$. The largest changes occur at the upper end of this scale, with changes from $95 \%$ to $90 \%$, for example, resulting in larger decreases in surface shortwave flux density than changes from $60 \%$ to $55 \%$. Throughout M-PACE, as solar zenith angle decreases, sensitivity to surface albedo is reduced substantially. This is also evident when comparing the sensitivities from this study to those from Shupe and Intrieri (2004), who demonstrated a decreased surface flux density of roughly $40 \mathrm{Wm}^{-2}$ for every 0.1 decrease in surface albedo for conditions featuring a $60^{\circ} \mathrm{SZA}, 0.6$ surface albedo and $50 \mathrm{gm}^{-2} \mathrm{LWP}$. For case one conditions (SZA of $75^{\circ}, 0.6$ surface albedo and $150 \mathrm{gm}^{-2}$ LWP) that sensitivity is closer to $5 \mathrm{Wm}^{-2}$ per 0.1 decrease in surface albedo due to the lower SZA and thicker cloud. In addition to the impact of surface albedo on shortwave flux densities, surface temperature impacts upwelling surface longwave radiation. For the cases from M-PACE, a five degree decrease in surface temperature resulted in a decrease in upwelling longwave surface flux density of roughly $20 \mathrm{Wm}^{-2}$.

\subsection{Derived cloud radiative forcing}

As an example of a tangible end-product derived from the calculated flux densities, cloud radiative forcing may be derived in a method similar to that used in
Ramanathan et al. (1989). Here the short and longwave radiative forcing are defined as:

$$
\begin{aligned}
& \mathrm{CF}_{\mathrm{LW}}=\mathrm{LW}_{\mathrm{NET}} \text { (cloudy) }-\mathrm{LW}_{\mathrm{NET}} \text { (clear) } \\
& \mathrm{CF}_{\mathrm{SW}}=\mathrm{SW}_{\mathrm{NET}} \text { (cloudy) }-\mathrm{SW}_{\mathrm{NET}} \text { (clear) } \\
& \mathrm{CF}=\mathrm{CF}_{\mathrm{LW}}+\mathrm{CF}_{\mathrm{SW}}
\end{aligned}
$$

where $\mathrm{LW}_{\mathrm{NET}}$ and $\mathrm{SW}_{\mathrm{NET}}$ the net surface long- and shortwave flux densities, respectively, and "cloudy" and "clear" terms represent the cloudy and clear-sky flux density, respectively. As in the rest of the paper, all flux densities are defined as positive downward. In order to determine the clear sky flux density, RRTMG was run on each case after removal of liquid and ice and adjustment of the temperature profile to remove inversions caused by cloud-top cooling. Inversions were removed via linear interpolation of temperature from the surface to the top of the cloud-induced inversion.

Cloud radiative forcing estimates from this calculation are presented in Fig. 6. Distributions of shortwave, longwave, and net cloud radiative forcing are provided for the 154 retrieved profiles. The contribution of nighttime and low light cases is evident in the large peak in shortwave forcing centered on $0 \mathrm{Wm}^{-2}$. The rest of the cases are distributed on the negative side between 0 and $-50 \mathrm{Wm}^{-2}$ (cloud results in reduced shortwave surface flux) due to variability in cloud properties and solar zenith angle. Longwave radiative forcing is positive, with a large peak around $75-85 \mathrm{Wm}^{-2}$. Both longwave and shortwave distributions are qualitatively similar to those collected by Shupe and Intrieri (2004) for a year of measurements from the SHEBA campaign. However, longwave cloud radiative forcing values are slightly higher (70-90 $\mathrm{Wm}^{-2}$ compared to $25-75 \mathrm{Wm}^{-2}$ ) when compared to the Shupe and Intrieri (2004) study. This is likely due to the short time period covered in the current study, and the likely inclusion of numerous thin liquid clouds in the oneyear SHEBA dataset. The longwave values are higher but comparable to those reported by Dong and Mace (2003) for summer months in Barrow (40-70 $\mathrm{Wm}^{-2}$ ). Short- and longwave cloud radiative forcing estimates for Barrow during October from Dong et al. (2010) were smaller in magnitude than those derived in the current study, but their analysis was not limited to mixed-phase clouds or liquid-containing clouds. Combined, the short- and longwave contributions result in a positive cloud radiative forcing for mixed-phase stratiform clouds observed during the M-PACE campaign. Net values range between roughly 25 and $90 \mathrm{Wm}^{-2}$, with a majority of cases falling in the $70-90 \mathrm{Wm}^{-2}$ range. This means that mixed-phase clouds increase incoming radiation at the surface due to the longwave contributions during the observed autumn period. An overview of mean cloud radiative forcing estimates is provided in Table 2 .

Figure 7 demonstrates the sensitivity of cloud radiative forcing to several relevant properties. In the top row, shortwave cloud forcing is normalized to remove variation due to 


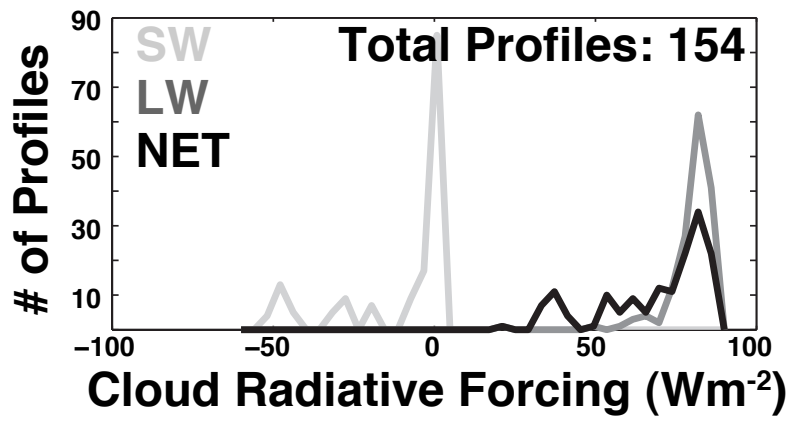

Fig. 6. Distributions of shortwave (SW, light grey), longwave (LW, dark grey) and net (black) cloud radiative forcing from M-PACE (09/2004-11/2004) cases.

solar zenith angle (SZA). Here, normalized cloud forcing is defined as:

$\mathrm{CF}_{\mathrm{SW}, \mathrm{NORM}}=\frac{\mathrm{SW}_{\mathrm{NET} \text { (clear) }}-\mathrm{SW}_{\mathrm{NET}} \text { (cloudy) }}{\mathrm{SW}_{\mathrm{NET}} \text { (clear) }}$

where $\mathrm{SW}_{\mathrm{NET}}$ (cloudy) is the calculated net cloud flux in the presence of clouds, and $\mathrm{SW}_{\mathrm{NET}}$ (clear) is the value calculated under clear sky conditions, as described above. The remaining rows show calculated cloud radiative forcing as described in Eqs. (5)-(7). Nighttime cases are not included in this top row, since the denominator of Eq. (8) would be zero.

On the far left, normalized shortwave, absolute shortwave, longwave and net radiative forcing are shown as a function of SZA as observed during M-PACE. As expected, absolute shortwave cloud radiative forcing becomes more negative with decreasing SZA (decreasing SZA means that the sun is higher in the sky). Cases for which the SZA were 90 degrees are indicative of a sun that is at or below the horizon, and all calculated SZA values higher than 90 were set to 90 degrees. While longwave forcing is shown to decrease with increasing SZA, this is likely due to decreases in temperature at later times of year. The second column from the left demonstrates the relationship between liquid optical depth and cloud radiative forcing. The most noticeable influence is on the longwave cloud forcing, with a sharp decrease in cloud forcing associated with very low optical depths. This is due to a cold overlying atmosphere combined with increased cloud transmissivity in cases with low optical depths. A similar effect can be seen with the ice water optical depth (center column), though it is not nearly as well-defined. Shortwave cloud forcing is also impacted by liquid optical depth, as can be seen by the normalized analysis in the top row. As may be expected, optically thicker clouds force the surface radiation more strongly than thin clouds.

The effect of cloud base temperature is shown in the second column from the right. As expected, lower cloud base temperatures result in decreased longwave cloud radiative forcing at the surface. In the cases presented, it appears as
Table 2. Mean cloud radiative forcing for M-PACE mixed-phase clouds by case, and for the entire period. The M-PACE mean shortwave cloud radiative forcing does not include nighttime cases.

\begin{tabular}{lrrr}
\hline Case & $\overline{\mathrm{CRF}_{\text {Sw }}}$ & $\overline{\mathrm{CRF}_{\mathrm{lw}}}$ & $\overline{\mathrm{CRF}_{\mathrm{nt}}}$ \\
\hline 1 & -48.6 & 82.1 & 33.5 \\
2 & 0.0 & 79.9 & 79.9 \\
3 & 0.0 & 85.1 & 85.1 \\
4 & -45.7 & 84.9 & 39.3 \\
5 & 0.0 & 81.6 & 81.6 \\
6 & -49.8 & 86.1 & 36.4 \\
7 & 0.0 & 83.6 & 83.6 \\
8 & -19.3 & 82.7 & 63.5 \\
9 & 0.0 & 84.5 & 84.5 \\
10 & -28.5 & 83.7 & 55.2 \\
11 & -7.7 & 78.6 & 70.1 \\
12 & -2.0 & 74.1 & 72.1 \\
13 & 0.0 & 82.3 & 82.3 \\
14 & 0.0 & 76.9 & 76.9 \\
15 & 0.0 & 58.8 & 58.8 \\
16 & -1.2 & 78.2 & 76.7 \\
\hline M-PACE & -25.3 & 80.2 & 67.5 \\
\hline
\end{tabular}

though clouds with the lowest liquid water optical depth also featured the lowest cloud base temperatures. Consequently, for non-nighttime cases shortwave cloud radiative forcing also increases in magnitude (becomes more negative) with increasing cloud base temperature. Because this relationship holds in the normalized analysis, this is not simply a result of colder clouds occurring at times with low sun angles, but rather that optically thinner clouds were found to occur at colder temperatures. Although there are physical reasons that this may not be surprising (i.e. increased ice nucleation or decreased moisture availability under colder conditions), the small subset of cases sampled here does not allow for the construction of concrete general conclusions. Longwave cloud radiative forcing demonstrates a relationship to cloud thickness similar to that of the liquid optical thickness. Clouds over approximately $600 \mathrm{~m}$ thick had similar longwave cloud radiative forcing of $75 \mathrm{Wm}^{-2}$ or larger. As with cloud base temperature, normalized shortwave cloud radiative forcing demonstrates a clear relationship to cloud thickness. This relationship is masked by SZA contributions in the raw forcing calculation.

\section{Summary}

Surface radiative properties were estimated for mixed-phase cloud conditions observed during M-PACE using a combination of modern cloud remote-sensors, current cloud measurements and retrievals and an advanced radiative transfer model. Using profiles of cloud properties such as liquid and ice water paths, cloud heights, effective particle sizes and 

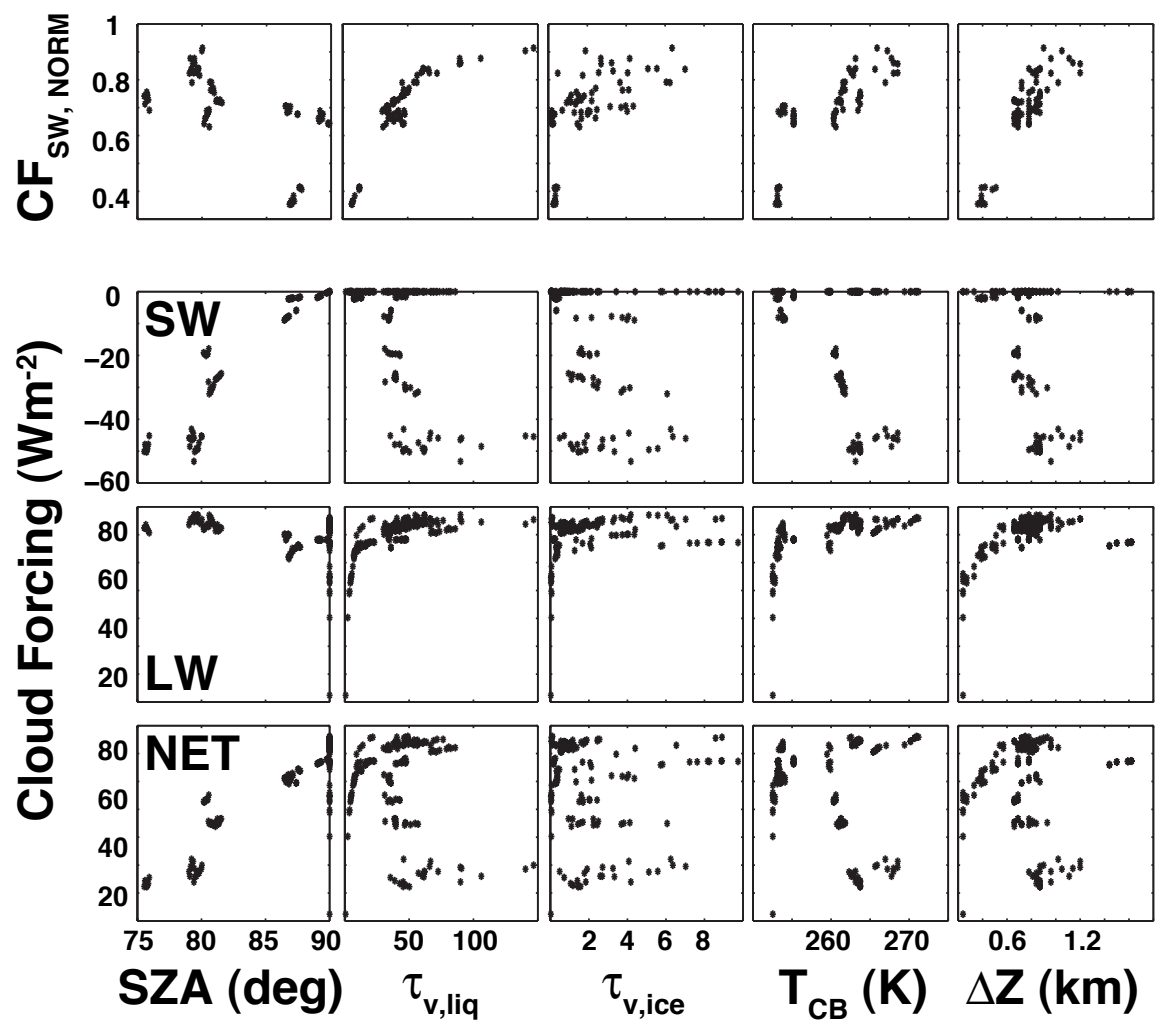

Fig. 7. Shortwave (SW, top), longwave (LW, middle) and net (bottom) cloud radiative forcing as a function of (from left to right) solar zenith angle (SZA), visible liquid optical depth $\left(\tau_{v}\right.$,liq $)$, visible ice optical depth $\left(\tau_{v, \text { liq }}\right)$, cloud base temperature $\left(T_{\mathrm{CB}}\right)$, and cloud thickness $(\Delta Z)$ for profiles observed during M-PACE.

temperature profiles to drive the radiative transfer model, a total of 16 mixed-phase cloud periods were evaluated, resulting in 154 two-minute mixed-phase cloud observations. This technique was demonstrated to generally agree well with surface radiometric estimates, with the magnitude of most errors falling below $10 \mathrm{Wm}^{-2}(61 \%, 72 \%, 97 \%, 95 \%, 76 \%$ and $79 \%$ of total profiles for downwelling shortwave, upwelling shortwave, net shortwave, downwelling longwave, upwelling longwave, and net longwave, respectively). For shortwave radiation, errors were found to be largest for clouds with thicker liquid components, and were generally found to be negative, meaning the model flux densities were too low when compared to the observations. Errors in downwelling longwave radiation were largest for clouds with low LWP, and generally positive, meaning the model flux densities were too high compared to those observed.

In order to better understand the capabilities of this technique in estimating surface radiative properties, a sensitivity analysis was completed. This analysis included 56 additional radiative transfer experiments, with each one covering all of the observed profiles. Sensitivity tests were completed to understand the individual impacts of different retrieval as- sumptions (e.g. ice crystal habit, cloud base effective droplet size) and of measurement errors (e.g. MWR-retrieved LWP, radar-retrieved IWP), along with a combined, net impact incorporating all possible combinations of individual tests. The liquid droplet size assumed at cloud base was found to have the largest impact on downwelling shortwave fluxes, while ice crystal habit and ice water content uncertainty impacted the downwelling longwave component most strongly. With the exception of the impact of liquid droplet size on surface shortwave radiation, variation of different retrieval parameters generally lead to small $\left(<5 \mathrm{Wm}^{-2}\right)$ differences in surface fluxes. Various parameters could result in larger uncertainties when combined, resulting in net uncertainties of -25 to $15 \mathrm{Wm}^{-2}$ in the shortwave, and -5 to $5 \mathrm{Wm}^{-2}$ in the longwave.

As a demonstration of the utility of these calculations, cloud radiative forcing for M-PACE mixed-phase clouds was calculated. Shortwave forcing was generally small, due in part to the contribution of nighttime cases, and in part to low sun-angles during this time of year. The largest shortwave forcing occurred early in the observation period and was roughly $-50 \mathrm{Wm}^{-2}$. Longwave cloud forcing was always 
positive, with most values falling between $70-90 \mathrm{Wm}^{-2}$. Combined with the shortwave forcing, this resulted in net cloud forcing ranging between $25-90 \mathrm{Wm}^{-2}$. This demonstrates that these clouds act to warm the surface during the fall, which agrees with findings presented in several other studies (e.g. Schweiger and Key, 1994; Intrieri et al., 2002; Shupe and Intrieri, 2004).

The information presented here is relevant to understanding the impact of clouds on a changing surface state. The radiative impacts of specific cloud types on the freezing and melting of sea ice, permafrost and glaciers, for example are just beginning to be explored. Results presented provide guidance on use of this technique for expanding our knowledge of mixed-phase cloud forcing at observational sites that have cloud remote sensors but lack or have limited radiometric instrumentation. Future work will focus on application of this method to larger datasets, and exploration of the radiative impact of mixed-phase stratiform clouds on surface ice melting rates. Doing so will provide information on the relevance of clouds and cloud-aerosol effects on the climate system, as well as help us to understand how simulated future changes in cloud types and cloud cover may impact the surface state.

Acknowledgements. LBNL research was supported by the Director, Office of Science, Office of Biological and Environmental Research of the U.S. Department of Energy under Contract No. DE-AC02-05CH11231 as part of their Climate and Earth System Modeling Program. Long is supported by the Office of Biological and Environmental Research (OBER) of the U.S. Department of Energy (DOE) as part of the Atmospheric Radiation Measurement (ARM), and Atmospheric Systems Research (ASR) Programs. The Pacific Northwest National Laboratory (PNNL) is operated by Battelle for the DOE under contract DE-AC06-76RLO 1830 . LBNL is managed by the University of California under U.S. DOE grant DE-AC02-05CH11231. The authors would like to thank Michael Iacono and the Atmospheric and Environmental Research (AER) team for their help in setting up RRTMG. In addition, we would like to thank the University of Wisconsin Lidar Group for making data from the M-PACE period available for evaluation via their website at http://lidar.ssec.wisc.edu, and the M-PACE crew for their hard work in compiling the datasets used. Funding for M-PACE was provided by the United States Department of Energy. This work was prepared in part at the Cooperative Institute for Research in Environmental Sciences (CIRES) with support in part from the National Oceanic and Atmospheric Administration, U.S. Department of Commerce, under cooperative agreement NA17RJ1229 and other grants. The statements, findings, conclusions, and recommendations are those of the author and do not necessarily reflect the views of the National Oceanic and Atmospheric Administration or the Department of Commerce. Computing resources were provided by NASA and the US Department of Energy. The authors wish to recognize the efforts that went into collection and construction of the various datasets used in the present study.

Edited by: B. Mayer

\section{References}

Barkstrom, B., Harrison, E., and Lee, R.: Earth Radiation Budget Experiment: Preliminary seasonal results, EOS, 71, 6 pp., 1990.

Clough, S., Shephard, M., Mlawer, E., Delamere, J., Iacono, M., Cady-Pereira, K., Boukabara, S., and Brown, P.: Atmospheric radiative transfer modeling: a summary of the AER codes, J. Quant. Spectrosc. Radiat. Transfer, 91, 233-244, 2005.

Curry, J. and Ebert, E.: Annual cycle of radiation fluxes over the Arctic Ocean: Sensitivity to cloud optical properties, J. Clim., 5, 1267-1280, 1992.

Curry, J. and Herman, G.: Infrared radiative properties of summertime Arctic stratus clouds, J. Clim. Appl. Meteorol., 24, 525538, 1985.

Curry, J., Rossow, W., Randall, D., and Schramm, J.: Overview of Arctic Cloud and Radiation Characteristics, J. Climate, 9, 17311764, 1996.

de Boer, G., Tripoli, G. J., and Eloranta, E. W.: Preliminary comparison of CloudSAT-derived microphysical quantities with ground-based measurements for mixed-phase cloud research in the Arctic, J. Geophys. Res., 113, D00A06, doi:10.1029/2008JD010029, 2008.

de Boer, G., Eloranta, E., and Shupe, M.: Arctic Mixed-Phase Stratiform Cloud Properties from Multiple Years of Surface-Based Measurements at Two High-Latitude Locations, J. Atmos. Sci., 66, 2874-2887, doi:10.1175/2009JAS3029.1, 2009.

de Boer, G., Hashino, T., and Tripoli, G. J.: A Theory for Ice Nucleation Through Immersion Freezing in Mixed-Phase Stratiform Clouds, Atmos. Res., 96, 315-324, doi:10.1016/j.atmosres.2009.09.012, 2010.

Dong, X. and Mace, G.: Arctic stratus cloud properties and radiative forcing derived from ground-based data collected at Barrow, Alaska, J. Clim., 16, 445-461, 2003.

Dong, X., Xi, B., Crosby, K., Long, C., Stone, R., and Shupe, M.: A 10 year climatology of Arctic cloud fraction and radiative forcing at Barrow, Alaska, J. Geophys. Res., 115, D17 212, doi:10.1029/2009JD013489, 2010.

Donovan, D. and van Lammeren, A.: Cloud effective particle size and water content profile retrievals using combined lidar and radar observations I - Theory and examples, J. Geophys. Res., 105, 27425-27488, 2001.

Ebert, E. and Curry, J.: A parameterization of ice cloud optical properties for climate models, J. Geophys. Res., 97, 3831-3836, 1992.

Eloranta, E.: High Spectral Resolution Lidar, in: Lidar: RangeResolved Optical Remote Sensing of the Atmosphere, edited by: Weitkamp, K., 143-163, Springer-Verlag, New York, USA, 2005.

Intrieri, J., Fairall, C., Shupe, M., Persson, P., Andreas, E., Guest, P., and Moritz, R.: An annual cycle of Arctic surface cloud forcing at SHEBA, J. Geophys. Res., 107, 14 pp., doi:10.1029/2000JC000439, 2002.

IPCC: Climate Change 2007: The Physical Science Basis, Tech. rep., 2007.

Kay, J. and Gettelman, A.: Cloud influence on and response to seasonal Arctic sea ice loss, J. Geophys. Res., 114, D18 204, doi:10.1029/2009JD011773, 2009.

Long, C. and Shi, Y.: An automated quality assessment and control algorithm for surface radiation measurements, TOASJ, 2, 23-37, 2008. 
Long, C. and Turner, D.: A method for continuous estimation of clear-sky downwelling longwave radiative flux developed using ARM surface measurements, J. Geophys. Res., 113, D18206, doi:10.1029/2008JD009936, 2008.

McFarquhar, G., Zhang, G., Poellot, M., Kok, G., McCoy, R., Tooman, T., Fridlind, A., and Heymsfield, A.: Ice Properties of Single-Layer Stratocumulus During the Mixed-Phase Arctic Cloud Experiment: 1. Observations, J. Geophys. Res., 112, D24201, doi:10.1029/2007JD008633, 2007.

Mitchell, D.: Use of mass- and area-dimensional power laws for determining precipitation particle terminal velocities, J. Atmos. Sci., 53, 1710-1723, 1996.

Moran, K., Martner, B., Post, M., Kropfli, R., Welsch, D., and Widener, K.: An unattended cloud-profiling radar for use in climate research, Bull. Am. Meteorol. Soc., 79, 443-455, 1998.

Pinto, J.: Autumnal Mixed-Phase Cloudy Boundary Layers in the Arctic, J. Atmos. Sci., 55, 2016-2038, 1998.

Prowse, T., Furgal, C., Wrona, F., and Reist, J.: Implications of climate change for northern Canada: freshwater, marine, and terrestrial ecosystems, Ambio, 38, 282-289, 2009.

Ramanathan, V., Cess, R., Harrison, E., Minnis, P., Barkstrom, B., Ahmad, E., and Hartman, D.: Cloud-radiative forcing and climate: Results for the Earth Radiation Budget Experiment, Science, 243, 57-63, 1989.

Schweiger, A. and Key, J.: Arctic Ocean radiative fluxes and cloud forcing estimates from the ISCPP C2 cloud dataset, 1983-1990, J. Appl. Meteorol., 33, 948-963, 1994.

Shupe, M. and Intrieri, J.: Cloud radiative forcing of the Arctic surface: The influence of cloud properties, surface albedo, and solar zenith angle, J. Climate, 17, 616-628, 2004.

Shupe, M., Matrosov, S., and Uttal, T.: Arctic Mixed-Phase Cloud Properties Derived from Surface-Based Sensors at SHEBA, J. Atmos. Sci., 63, 697-711, 2006.
Shupe, M., Daniel, J., de Boer, G., Eloranta, E., Kollias, P., Long, C., Luke, E., Turner, D., and Verlinde, J.: A Focus on MixedPhase Clouds: The Status of Ground-Based Observational Methods, Bull. Am. Meteorol. Soc., 87, 1549-1562, 2008a.

Shupe, M., Kollias, P., Poellot, M., and Eloranta, E.: On deriving vertical air motions from cloud radar Doppler spectra, J. Atmos. Oceanic Technol., 25, 547-557, 2008b.

Stephens, G.: Remote sensing of the lower atmosphere, Oxford University Press, 1994.

Stoffel, T.: Solar Infrared Radiation Station (SIRS) handbook, Tech. Rep. TR-025, Atmospheric Radiation Measurement Program, 2005.

Uttal, T., Curry, J., McPhee, M., Perovich, D., Moritz, R., Maslanik, J., Guest, P., Stern, H., Moore, J., Turenne, R., Heiberg, A., Serreze, M., Wylie, D., and Persson, P.: Surface Heat Budget of the Arctic Ocean, Bull. Am. Meteorol. Soc., 83, 255-275, 2002.

Verlinde, J., Harrington, J., McFarquhar, G., Yannuzzi, V., Avramov, A., Greenberg, S., Johnson, N., Zhang, G., Poellot, M., Mather, J., Turner, D., Eloranta, E., Zak, B., Prenni, A., Daniel, J., Kok, G., Tobin, D., Holz, R., Sassen, K., Spangenberg, D., Minnis, P., Tooman, T., Ivey, M., Richardson, S., Bahrmann, C., Shupe, M., De Mott, P., Heymsfield, A., and Schofield, R.: The Mixed-Phase Arctic Cloud Experiment, Bull. Am. Meteorol. Soc., 88, 205-221, 2007.

Westwater, E., Han, Y., Shupe, M., and Matrosov, S.: Analysis of integrated cloud liquid and precipitable water vapor retrievals from microwave radiometers during the Surface Heat Budget of the Arctic Ocean project, J. Geophys. Res., 106, 32019-23030, 2001.

Zuidema, P., Baker, B., Han, Y., Intrieri, J., Key, J., Lawson, P., Matrosov, S., Shupe, M., Stone, R., and Uttal, T.: An Arctic Springtime Mixed-Phase Boundary Layer Observed During SHEBA, J Atmos. Sci., 62, 160-176, 2005. 